\title{
STRATEGI KOMUNIKASI SIARAN RADIO GEN 98.7 FM JAKARTA DALAM PROGRAM SIARAN DJ SORE UNTUK MEMPERTAHANKAN PENDENGAR
}

\author{
Annastasya Rizqa Prisanastiti ${ }^{1}$, Djudjur Luciana Radjagukguk ${ }^{1}$ \\ ${ }^{1}$ Program Studi Ilmu Komunikasi, Universitas Nasional \\ email : annastasyarizqa@gmail.com,djudjurluciana01@gmail.com
}

Korespondensi : djudjurluciana01@gmail.com

\begin{abstract}
The number of private radio stations accompanied by technological advancements is a challenge for Radio Gen 98.7 FM Jakarta especially in the afternoon broadcast program called 'DJ Afternoon' to retain its listeners. Thus, Radio Gen 98.7 FM Jakarta applies a communication strategy to the mature DJ Sore broadcast program which includes planning, carrying out the implementation and finally conducting an evaluation to find out what works and what is lacking in the planning. The method used is a qualitative method with a descriptive qualitative approach. The process of collecting data used in-depth interview techniques, indirect observation and documentation. The data obtained were then analyzed descriptively. The results of the research process of the radio communication strategy Gen 98.7 FM in the Afternoon DJ program are using POAC Theory proposed by George R. Terry, namely planning, organizing, actuating, and controlling. The DJ Afternoon broadcast program is made based on the wishes of the crew on Gen 98.7 FM radio to create broadcast programs that can accompany their listeners both during their evening activities or while on their way home. This encourages the managers of the DJ Sore broadcast program to create interesting concepts and features that will later be available in the DJ Sore broadcast program.
\end{abstract}

Keywords: communication strategy, radio broadcast program, listener, radio, dj sore

\begin{abstract}
Abstrak
Banyaknya stasiun radio swasta diiringi dengan kemajuan teknologi menjadi tantangan bagi Radio Gen 98.7 FM Jakarta khususnya di program siaran sore bernama 'DJ Sore' untuk mempertahankan pendengarnya. Sehingga, Radio Gen 98.7 FM Jakarta menerapkan strategi komunikasi pada program siaran DJ Sore yang matang meliputi perencanaan, melakukan pelaksanaan hingga yang terakhir melakukan evaluasi untuk mengetahui yang berhasil dan yang kurang dari perencanaan itu. Metode yang digunakan adalah metode kualitatif dengan pendekatan kualitatif deskriptif. Proses pengumpulan data yang digunakan teknik wawancara mendalam, observasi secara tidak langsung dan dokumentasi. Data-data yang diperoleh pun kemudian dianalisis secara deskriptif. Hasil penelitian dari proses strategi komunikasi radio Gen 98.7 FM pada dalam program DJ Sore adalah dengan menggunakan Teori POAC yang
\end{abstract}


dikemukakan oleh George R. Terry, yaitu perencanaan (planning), pengorganisasian (organizing), pelaksanaan (actuating), dan pengawasan (controlling). Program siaran DJ Sore dibuat berdasarkan keinginan para crew di radio Gen 98.7 FM untuk membuat program siaran yang dapat menemani para pendengarnya baik saat beraktifitas saat sore hari atau ketika sedang dalam perjalanan pulang. Hal tersebut mendorong para pengelola program siaran DJ Sore membuat konsep dan fitur-fitur menarik yang nantinya akan ada di program siaran DJ Sore.

Kata kunci: strategi komunikasi, program siaran radio, pendengar, radio, dj sore

\section{PENDAHULUAN}

Di era digital seperti saat ini, radio terus mengalami perkembangan yang pesat untuk menyampaikan informasi kepada masyarakat. Perkembangan yang dialami oleh media radio tak luput dari berkembangnya zaman dan teknologi, juga dari suatu strategi perusahaan yang menuntut kecepatan dan kemudahan dalam mengakses informasi. Daya tarik suatu radio juga dilihat dari jenis-jenis programnya. Berbagai jenis program radio yang bisa di dengar adalah program musik berita, dan non berita. Program berita meliputi berita hardnews seputar ekonomi dan politik, sedangkan program non berita seperti talkshow dan variety show. Kemudian program musik meliputi berbagai jenis genre, seperti pop, rock, jazz hingga dangdut. Kini radio tak hanya dikenal sebagai media elektronik yang hanya dapat diakses dengan frekuensi saja, hadirnya streaming dalam radio kini mempemudah para pendengar untuk mengakses radio favoritnya hanya dengan mengunduh aplikasi.

Salah satu radio tanah air yang tersohor dan tetap mengikuti perkembangan zaman ialah Radio Gen FM. Radio Gen FM merupakan salah satu radio di Indonesia yang masih eksis sejak tahun 2007 hingga sekarang. Saat ini, Radio Gen FM berada di dua kota besar, yaitu Jakarta dan Surabaya. Meski berada di kota yang berbeda, baik Radio Gen FM Jakarta maupun Surabaya memiliki format yang sama, yaitu radio hiburan anak muda.

Strategi komunikasi pada dasarnya merupakan sebuah perencanaan atau tahapan untuk mencapai tujuan yang efektif. Setiap strategi memiliki tujuan yaitu keefektifan dari pesan yang disampaikan. Strategi sendiri pun memiliki tahapan mulai dari planning (perencanaan), dimana seseorang akan menentukan terelebih dahulu apa saja yang dilakukan dimasa yang akan datang, kemudian organizing, merupakan pembagian tugas, siapa melakukan apa dengan tanggung jawab apa, lalu actuating, dimana rencana yang telah disiapkan diimplementasikan untuk melihat hasilnya secara nyata, lalu controlling, dilakukan untuk memonitori apakah rencana yang diimplementasikan berjalan dengan baik atau tidak. Sampai kepada evaluation (evaluasi), dimana semua strategi atau rencana yang sudah diimplementasikan dinilai apakah sudah berjalan dengan baik atau belum. Jika sudah maka akan dipergunakan lagi dikemudian hari. Namun jika gagal, perlu direvisi, dimana letak kegagalan itu terjadi.

Bicara soal strategi, berarti berbicara bagaimana untuk mencapai tujuan. Maka dari itu, suatu perusahaan harus menggunakan strategi atau tahapan-tahapan 
guna mencapai tujuan yang efektif. Dari empat tahapan, jika dilakukan secara tepat dan benar dapat memungkinkan suatu perusahaan berjalan dengan stabil. Melalui penelitian ini, ingin diketahui lebih dalam bagaimana Planning, Organizing, Actuating dan Controlling yang dilakukan radio Gen 98.7 FM dalam program 'DJ Sore' untuk mempertahankan pendengarnya.

Strategi komunikasi merupakan percampuran antara perencanaan komunikasi (communication planning) dengan manajemen komunikasi (communication management) untuk mencapai tujuan yang telah ditetapkan. Strategi komunikasi harus mampu menunjukan bagaimana operasionalnya secara praktis harus dilakukan, dalam arti kata pendekatannya bisa berbeda-beda tergantung pada suatu kondisi dan situasi (Onong Effendy Uchjana, 1992).

Seperti yang dijabarkan oleh (Muhammad Arni 2004), menjelaskan strategi komunikasi yaitu semua yang terkait mengenai rencana dan taktik atau cara yang akan dipergunakan untuk melencarkan komunikasi dengan menampilkan pengirim, pesan dan penerimanya pada proses komunikasi untuk mencapai tujuan yang diinginkan. Startegi komunikasi bisa dikatakan sebagai suatu pola pikir dalam merencanakan suatu kegiatan, mengubah sikap, sifat, pendapat, dan perilaku khalayak (komunikan, hadirin, mad'u) atas dasar skala yang luas melalui penyampaian gagasan Kustadi Suhandang (2014).

Strategi komunikasi dipahami bahwa strategi komunikasi merupakan sebuah perencanaan, rancangan, atau taktik yang dipergunakan untuk menjadikan proses komunikasi yang efektif guna untuk mencapai tujuan yang diinginkan.

Dalam komunikasi, penyampaian pesan dan feedback yang efektif menjadi tujuan utama. Maka dari itu, dibutuhkan strategi yang baik. Jika tidak ada strategi komunikasi yang baik, efek dari proses komunikasi (terutama komunikasi media massa) bukan tidak mungkin akan menimbulkan pengaruh negatif. Menurut $\mathrm{R}$. Wayne Pace, Brent D. Peterson, dan M. Dallas Burnett, dikutip dari buku Onong Ucjana Effendi (2000) berjudul Komunikasi Teori dan Praktek menyatakan bahwa tujuan sentral komunikasi terdiri dari tiga tujuan. Pertama ialah to secure understanding, yaitu memastikan bahwa komunikan mengerti pesan yang diterimanya. Andaikata ia sudah dapat mengerti dan menerima, maka penerimaannya itu harus dibina (to established acceptence). Pada akhirnya kegiatan dimotivasikan (to motivate action). Garis besarnya, strategi komunikasi memang sangat dibutuhkan untuk berhasil mencapai suatu tujuan secara efektif dan dengan menggunakan upaya-upaya yang telah dirancang sebelumnya. Strategi komunikasi akan berhasil jika menggunakan komponen-komponen yang ada.

Menurut Syam dan kawan-kawan di Perencanaan Pesan dan Media (dalam buku Strategi Komunikasi Dwi Kartikawati, Djudjur Luciana, Yayu Sriwartini, (2019) suatu strategi pada dasarnya memiliki unsur-unsur, antara lain:

a. Strategi Komunikator

Dalam hal strategi komunikator, maka dua hal yang harus dilakukan, yaitu, penentuan sasaran komunikasi, penentuan cara berkomunikasi, dan kredibilitas komunikator. Sasaran komunikasi dapat diartikan bahwa segala sesuatu yang kita sampaikan kepada komunikan hendaknya bersifat "lurus" kearah sasaran yang ingin kita capai. Kemudian penentuan cara berkomunikasi meliputi bagaimana 
seorang komunikator harus membawa dirinya di depan khalayak. Dengan kata lain, komunikator harus bisa mengontrol atau mengendalikan pesan komunikasi yang ia sampaikan. Terakhir kredibilitas komunikator, yaitu kondisi dimana omunikator dinilai memiliki keahlian, pengetahuan atau pengalaman yang relevan dengan topik pesan yang disampaikan, sehingga komunikan menjadi percaya.

b. Strategi Khalayak

Yaitu analisis situasi komunikasi dari sudut pandang khalayak. Dalam hal tersebut, terdapat beberapa pertimbangan-pertimbangan yang harus diperhatikan, yaitu identifikasi khalayak, yang terbagi menjadi khayalak primer, sekunder, dan gatekeeper. Khalayak primer adalah mereka yang langsung menerima pesan komunikasi pada saat mereka hadir atau berpartisipasi secara langsung dengan kegiatan komunikasi. Lalu khalayak sekunder, merupakan orang-orang yang akan mendengar pesan komunikasi (yang tidak hadir langsung) yang merasa perlu mendapatkan hasil konfirmasi dari orang-orang lain yang mungkin terpengaruh oleh pesan komunikasi. Kemudian gatekeeper, yakni mereka yang hadir secara langsung ketika komunikator menyampaikan pesan kepada mereka. Namun mereka hanya menjadi perantara yang akan meneruskan informasi yang mereka terima kepada pihak yang berkepentingan.

c. Strategi Pesan

Dalam strategi pesan maka akan melibatkan dua hal, yaitu penekanan inti pokok pesan, dan pengorganisasian pesan. Komunikator perlu memahami inti pokok dari pesan yang akan disebarkan kepada komunikannya. Dengan kata lain, komunikator harus mengetahui segementasi komunikannya agar pesan yang disampaikan mendapatkan feedback yang sesuai. Kemudian pengorganisasian pesan.

d. Strategi Pemilihan Channel

Strategi pemilihan channel berkenaan dengan pertimbangan kapan kita harus berbicara dan kapan kita harus menulis. Dengan kata lain, kapan kita harus menyampaikan pesan komunikasi secara lisan dan kapan secara tulisan.

e. Strategi Budaya

Pada strategi budaya, yang harus dilakukan adalah pertimbangan semua unsur yang terlibat dalam strategi komunikasi dan meletakkannya dalam konteks budaya tertentu.

Dari pemaparan konsep unsur-unsur strategi komunikasi diatas, memahami strategi komunikator yang dimaksud dalam radio Gen 98.7 FM adalah penyiar. Dengan kata lain, penyiar radio Gen 98.7 FM di program DJ Sore harus memperhatikan sasaran komunikasinya (pendengar), yaitu anak muda. Penyiar radio Gen 98.7 FM program DJ Sore juga harus memiliki kredibilitas di bidangnya. Dengan kata lain, penyiar radio Gen 98.7 FM Jakarta harus menguasai konsep dari program siarannya tersebut.

Kemudian dari strategi khalayak, dimana pendengar radio Gen 98.7 FM di program siaran DJ Sore harus diidentifikasi dari sudut pandang masyarakat. dengan kata lain, radio Gen 98.7 FM perlu memahami siapa komunikan (pendengar) yang akan mendengar program siaran DJ Sore. Sari strategi pesan, dimana komunikator 
(penyiar) radio Gen 98.7 FM program siaran DJ Sore harus memahami inti pokok dari pesan yang akan disampaikan pada komunikannya (pendengar) serta cara pengorganisasinnya. Hal tersebut agar pesan yang disampaikan tepat pada sasaran atau sesuai dengan sasaran pendengarnya. Kemudian dari segi strategi pemilihan media. Dimana stasiun radio pemilihan channelnya merupakan pendengaran. Lalu dari segi strategi budaya. Hal ini komunikator perlu memahami budaya pendengarnya. Dalam hal ini, gaya bahasa yang digunakan penyiar radio Gen 98.7 FM di program DJ Sore adalah bahasa 'gaul' yang mudah di mengerti pendengar sesuai dengan segmentasinya.

\section{METODE}

Pendekatan yang dilakukan melalui pendekatan kualitatif. Dimana data yang dikumpulkan berupa kata-kata, gambar, dan bukan angka-angka. Penelitian ini pun akan mengungkapkan kejadian atau fenomena yang sesungguhnya pada saat peneliti terjun ke lapangan dan diperkuat dengan hasil dari observasi, wawancara dan dokumentasi (Lexy J. Moleong, 2018). Teknik pengumpulan data dilakukan untuk mendapatkan data yang valid untuk menunjang hasil penelitian. Dalam prosesnya, teknik pengumpulan data harus melewati beberapa langkah bertujuan untuk memperoleh data-data dari informan. Hal tersebut harus dilakukan supaya terarah dan sesuai dengan tujuan yang ingin dicapai. Sehingga menggunakan beberapa teknik pengumpulan data sebagai berikut wawancara, observasi dan dokumentasi.

Pada penelitian ini, untuk memudahkan menganalisis data yang didapat, melakukan teknik analisis data model Miles dan Hubermen (1992) yang terdiri dari tiga komponen, yakni reduksi data, penyajian data, dan penarikan kesimpulan. Teknik ini dipilih untuk memudahkan penulis mengemukakan gambaran dari hasil penelitian yang dilaksanakan.

\section{HASIL DAN PEMBAHASAN}

Strategi komunikasi pada dasarnya merupakan suatu perencanaan yang dibuat untuk mencapai tujuan yang ditetapkan. Adapun unsur-unsur strategi komunikasi meliputi, strategi komunikator, strategi khalayak, strategi pesan, strategi pemilihan media (channel) dan strategi budaya.

Proses strategi komunikasi Radio Gen 98.7 FM Jakarta dalam program siaran DJ Sore yang dilakukan oleh pengelola program diawali dengan tahap perencanaan, pengorganisasian, pelaksanaan dan pengawasan. Fungsi-fungsi dari teori POAC diatas berpengaruh besar dalam mendukung strategi komunikasi program siaran DJ Sore untuk mempertahankan pendengarnya.

Adapun penerapan tahapan strategi komunikasi yang dijalankan radio Gen 98.7 FM pada program siaran DJ Sore sebagai berikut:

\section{Perencanaan (Planning) Program Siaran "DJ Sore"}

Dalam perencanaan strategi komunikasi Radio Gen 98.7 FM Jakarta dalam program siaran DJ Sore untuk mempertahankan pendengar, crew program siaran DJ Sore melakukan rapat terlebih dahulu untuk membahas perencanaan yang matang. 
Rapat tersebut dilaksanakan di Ruang Rapat Kantor Gen 98.7 FM Jakarta dan dihadiri oleh kepala program, produser, penyiar, kreatif dan script writer.

Sehingga perencanaan program siaran DJ Sore diawali untuk mengetahui karakter penyiar dengan konsep program yang akan dibawakan. Hal tersebut guna agar pesan atau materi yang disampaikan bisa diterima dan mendapatkan feedback yang baik dari pendengar. Dapat diartikan juga, strategi komunikasi yang dilakukan program DJ Sore untuk mempertahankan pendengarnya ialah menggunakan strategi komunikator. Yaitu penyiar dirasa perlu memahami sasaran pendengar, perlu menentukan cara berkomunikasi dan penyiar juga perlu diperhatikan kredibilitasnya. Dengan kata lain, penyesuain karakter penyiar yang dimaksud oleh produser DJ Sore Suluh Bagus bahwa penentuan teknik atau cara penyiar bersiaran guna pendengar DJ Sore menerima materi yang disiarkan dengan benar, baik dari segi kontennya maupun dari cara penyampaian komunikatornya (penyiar).

Dari pemaparan diatas, trend suatu peristiwa menjadi kunci sebuah materi yang disukai pendengar. Untuk itu, crew program DJ Sore berusaha sebisa mungkin mengulik peristiwa-peristiwa yang tengah terjadi dan sedang dinikmati khalayak. Hal tersebut dilakukan agar pendengar tetap bertahan mendengarkan program siaran DJ Sore karena materi yang disampaikan sedang hangat-hangatnya. Melalui pemaparan diatas, dapat diartikan bahwa strategi yang digunakan dalam perencanaan pembuatan materi siaran adalah startegi khalayak. Dimana menganalisis suatu komunikasi dari sudut pandangan khalayak. Dengan kata lain, menentukan sebuah materi untuk disiarkan berdasarkan apa yang sedang di sukai para pendengarnya. Dengan begitu, para pendengar DJ Sore akan tetap bertahan karena materi siaran yang disampaikan selalu up to date.

Berdasarkan uraian key informan I, Suluh Bagus, selaku produser dan key informan II, Leo Utomo, selaku penyiar program DJ Sore, penulis memahami bahwa perencanaan merupakan hal utama yang harus dilakukan dengan benar karena menyangkut dengan keinginan pasar. Perencanaan juga merupakan komponen utama yang menempati bagian terpenting jalannya program siaran DJ Sore. Maka dari itu, perlu dilakukan briefing sebelum siaran kepada para penyiar, agar penyiar bisa menyesuaikan teknik atau cara bersiarannya sesuai dengan konsep dari program DJ Sore. Sebagai komunikator dan eksekutor dari program siaran DJ Sore. Serta perlunya diadakan rapat untuk menetukan materi yang sedang dinikmati oleh khalayak pendengar.

\section{Pengorganisasian (organizing)}

Pada tahap pengorganisasian, program siaran DJ Sore membentuk sebuah crew yang bertugas untuk melancarkan jalannya perencanaan yang telah dibuat, seperti siapa melakukan apa dengan tanggung jawab apa. Crew yang terlibat di program siaran DJ Sore meliputi produser, music director, kreatif, script writer dan penyiar. Crew tersebut memiliki peran dan tanggung jawabnya masing-masing sesuai dengan tugas yang diberikan oleh kepala program. Pengorganisasian (organizing) yang dilakukan pengelola program siaran DJ Sore ialah menggunakan strategi komunikator, yaitu penentuan bagaimana seorang komunikator membawa dirinya di depan khalayak. Dengan kata lain, setiap crew harus memiliki kredibilitas 
sesuai dengan perannya masing-masing, agar tugas dan tanggung jawab yang diberikan dapat terlaksana dengan efektif. Tujuan pengorganisasian pada program siaran DJ Sore dengan menggunakan strategi komunikator adalah agar crew yang terlibat dapat dipercaya mengemban tugasnya dengan baik dan benar karena sudah disesuaikan dengan kredibilitas berdasarkan job desc yang diterima. Hal tersebut guna untuk meminimalisir kesalahan yang dapat terjadi di program siaran DJ Sore.

\section{Pelaksanaan (actuating)}

Pada tahap pelaksanaan, semua crew program siaran DJ Sore yang telah diatur di organizing terlibat untuk menjalankan tugas dan tanggung jawabnya masing-masing. Seperti kreatif mulai membuat konsep, fitur-fitur dan materi yang akan di siarkan di program siaran DJ Sore. Begitu juga dengan music director yang mulai meriset lagu-lagu, script writer mulai membuat skrip siaran yang sesuai dengan materi yang diberikan kreatif dan produser, lalu penyiar yang bertugas menyiarkan program acara tersebut sesuai dengan konsep dan materi yang telah disiapkan sesuai dengan keinginan sasaran pendengar. Dalam hal ini, program siaran DJ Sore menggunakan strategi pesan, yaitu menekankan pada inti pokok pesan dan pengorganisasian pesan. Dengan kata lain, pengelola program siaran DJ Sore membuat materi yang akan disiarkan sesuai dengan sasaran para pendengarnya. Jika dilihat dari riset yang telah dilakukan, program siaran DJ Sore ingin mengusung program siaran sore yang menghibur, unik dan berbeda dengan program siaran radio sore lainnya.

Pelaksanaan (actuating) yang dilakukan program siaran DJ Sore sesuai dengan rencana yaitu pada waktu sore hari pada pukul 16.00-20.00 WIB. Waktu tersebut merupakan jam prime time sebuah radio karena dirasa masyarakat baru saja selesai dengan aktivitasnya dan sedang dalam perjalanan pulang. Dalam hal ini, hasil rapat yang dilakukan setiap hari untuk membuat sebuah konten di program siaran DJ Sore mulai diimplementasikan disini. Dimana terbentuknya segmensegmen yang unik dan menarik berdasarkan apa yang sedang diminati khalayak pendengar.

\section{Pengawasan (controlling)}

Proses pengawasan akan menetukan seberapa jauh suatu rencana yang dibuat dapat mencapai tujuannya. Tidak hanya sebagai pengawas berjalannnya perencanaan, pengawasan juga dilakukan guna untuk memantau kinerja para kru untuk meminimalisirkan kesalahan yang dapat menghambat berhasilnya perencanaan. Dilihat dari hasil observasi penulis selama melakukan pengamatan secara tidak langsung kantor radio Gen 98.7 FM Jakarta pada 10 Januari 2020, penulis melihat bagaimana produser memantau kegiatan siaran program DJ Sore di segmen Koh Julid, dimana penyiar Leo Utomo dirasa terlalu frontal dalam teknik penyiarannya. Produser Suluh Bagus sempat menegur Leo. Pengawasan (controlling) yang dilakukan produser pada program siaran DJ Sore menggunakan strategi pesan dan strategi komunikator. Pengawasan menggunakan strategi pesan yaitu dimana produser program siaran DJ Sore mengawasi bagaimana isi konten yang dibuat oleh kreatif dan disiarkan penyiar. Demikian juga dengan pengawasan 
menggunakan strategi komunikator. Dimana produser mengawasi cara bersiaran penyiar. Memantau sekaligus memastikan bahwa penyiar sudah melakukan teknik bersiaran dengan baik dan sesuai konsep.

Tujuan dari pengawasan (controlling) pada program siaran DJ Sore ini adalah untuk mengetahui sejauh mana rencana yang telah dibuat dan di laksanakan serta untuk memberi peluang sekecil mungkin pada kesalahan yang bisa saja terjadi di program siaran DJ Sore.

\section{Evaluasi (evaluating)}

Dari semua yang sudah dilakukan program siaran DJ Sore, dimulai dari perencanaan (planning) sampai pengawasan (controlling), maka akan lebih afdol jika setiap organisasi juga melakukan evaluasi untuk mengetahui apa saja yang kurang dan apa saja yang berjalan dengan baik dan dapat digunakan dikemudian hari.

Proses evaluasi akan menentukan seberapa jauh suatu rencana dan tujuan yang sudah dicapai. Kegiatan evaluasi ini dilihat dari masing-masing individu dan tiap-tiap dari langkah yang sudah direncanakan untuk membandingkan dengan hasil perencanaan dengan hasil yang sebenarnya. Jika kedua kinerja tersebut tidak sama maka akan diperlukan langkah-langkah perbaikan. Pada observasi yang dilakukan penulis 15 Januari 2020, penulis memantau jalannya rapat evaluasi yang dihadiri oleh produser dan dua penyiar DJ Sore. Hasil dari evaluasi tersebut merupakan pemantauan dari segi para penyiar DJ Sore. Produser mengatakan bahwa gaya bersiaran para penyiar boleh santai, tapi harus tetap memperhatikan attitude dan jangan terlalu frontal. Proses evaluasi pada hari itu juga membahas tentang segmen Cerita (Chargeran Rohani Kita), dimana pendengar terlihat aktif saat live di media sosial Instagram. Hal tersebut dapat disimpulkan bahwa segmen Cerita Chargeran Rohani Kita-kita) mendapat respon positif dari para pendengar.

Kemampuan sebuah program radio untuk mempertahakan pendengarnya dapat diraih dengan berbagai macam strategi. Hal tersebut berkaitan dengan maraknya persaingan yang membuat semua crew yang bertugas harus terus memutar otak memikirkan strategi untuk tetap mempertahankan pendengar. Maka dari itu, strategi sebuah program radio untuk mempertahankan pendengarnya ialah menggunakan serangkaian tahapan strategi komunikasi dan teori POAC (plannin, organizin), actuatin), controlling dan evaluating).

Berdasarkan analisa temuan di lapangan dan hasil wawancara dengan para informan terhadap strategi komunikasi radio Gen 98.7 FM Jakarta dalam program siaran DJ Sore untuk mempertahankan pendengar, ada terdapat langkah-langkah yang sudah dilakukan oleh radio Gen 98.7 FM Jakarta pada program DJ Sore untuk membuat program siaran di sore hari yang unik dan menghibur para pendengarnya. Sehingga program siaran DJ Sore dibuat berdasarkan keinginan para crew di radio Gen 98.7 FM untuk membuat program siaran yang dapat menemani para pendengarnya baik saat beraktifitas saat sore hari atau ketika sedang dalam perjalanan pulang. Hal tersebut mendorong para pengelola program siaran DJ Sore membuat konsep dan fitur-fitur menarik yang nantinya akan ada di program siaran DJ Sore. 
Perlu diketahui bahwa bertahannya pendengar di program siaran DJ Sore tidak luput dari strategi komunikasi yang dibentuk untuk memaksimalkan jalannya program tersebut. Strategi komunikasi menurut Onong Ucjana Effendi, merupakan percampuran antara perencanaan komunikasi (communication planning) dengan manajemen komunikasi (communication management) untuk mencapai tujuan yang telah ditetapkan. Strategi komunikasi harus mampu menunjukan bagaimana operasionalnya secara praktis harus dilakukan, dalam arti kata pendekatannya bisa berbeda-beda tergantung pada suatu kondisi dan situasi. Dalam hal ini, strategi komunikasi juga memiliki unsur-unsur seperti strategi komunikator, strategi khalayak, strategi pesan, strategi pemilihan media dan strategi budaya yang perlu diperhatikan pada setiap program siaran.

Langkah awal pembentukan strategi pada program siaran DJ Sore adalah menggunakan teori POAC (planning, organizing, actuating, controlling) yang dikemukakan oleh George R. Terry. Dimulai dari perencanaan (planning) merupakan susunan atau langkah-langkah secara sistematik dan teratur untuk mencapai tujuan organisasi atau memecahkan masalah tertentu. Seperti yang dikemukaan George R. Terry (1953) lewat bukunya yang berjudul Prinsip-prinsip Manajemen menjelaskan, bahwa perencanaan merupakan sesuatu yang sangat diperlukan dan merupakan lengan intelektual dari perkembangan hari depan kita.

Dalam hal ini, crew dari radio Gen 98.7 FM pada program DJ Sore perlu menentukan perencanaan yang matang terlebih dahulu. Dari hasil wawancara dengan informan, bahwa perencanaan awal yang dilakukan crew program DJ Sore adalah dengan melakukan rapat penentuan materi yang dilaksanakan setiap hari dengan waktu yang fleksibel. Rapat tersebut dilakukan guna menemukan ide-ide mengenai peristiwa apa yang sedang ramai diperbincangkan oleh para pendengar yang kemudian di pilih untuk dijadikan materi siaran.

Kemudian dari segi komunikator. Dalam hal ini, komunikator yang dimaksud adalah penyiar dan komunikan adalah pendengar. Produser DJ Sore, Suluh Bagus menyatakan bahwa peran penyiar sangatlah penting, mengingat radio merupakan media yang hanya mengandalkan audio dan penyiar merupakan komunikator sekaligus eksekutor di program siaran DJ Sore. Maka dari itu, dibutuhkan penyesuain suara dan teknik bersiaran penyiar dengan konsep program siaran DJ Sore agar materi yang disampaikan dapat diterima dengan baik dan benar oleh para pendengar. Menurut pemahaman penulis berdasarkan uraian diatas, perencanaan (planning) pada suatu program merupakan hal yang penting terutama pada jalannya suatu program siaran DJ Sore di radio Gen 98.7 FM. Perencanaan tersebut juga dilakukan sebagai strategi untuk mempertahankan pendengar dengan membuat suatu segmen-segmen yang unik sesuai dengan keadaan dan situasi yang sedang digemari khalayak pendengar.

Suatu program siaran pun tidak lepas dari sebuah pengorganisasi (organizing). Hal tersebut dilakukan guna perencanaan yang telah dibuat dapat segera dilaksanakan dengan telah dibaginya setiap tugas dan tanggung jawab. Pengorganisasian (organizing), yaitu kepala program mulai membagikan job description masing-masing, siapa melakukan apa dengan tanggung jawab apa. Berdasarkan penelitian yang telah dilakukan, penulis memahami bahwa strategi 
yang dilakukan pada pengorganisasian di program DJ Sore ini adalah strategi komunikator. Dimana seluruh yang crew bertugas harus diperhatikan kredibilitasnya agar tugas dan tanggung jawab yang diberikan dapat dilakukan dengan sebaikbaiknya dan dapat meminimalisirkan kesalahan yang bisa saja terjadi di program siaran DJ Sore jika kredibilitas crew tidak diperhatian. Setelah mengetahui pembagian tugas dari program DJ Sore, mulailah pelaksanaan yang melibatkan semua anggota di program siaran DJ Sore untuk menjalankan tugas dan tanggung jawabnya masing-masing.

Adanya pelaksanaan pada sebuah program sangat penting, karena dengan adanya pelaksanaan, proses berjalannya perencanaan yang telah dibuat bisa segera terrealisasikan. Dari sinilah akan ditemukan apa saja yang menjadi hambatan dan tantangan untuk para crew program siaran DJ Sore untuk mempertahankan pendengar. Berdasarkan hasil wawancara dengan key informan I, Suluh Bagus hambatan dan tantangan tersebut meliputi berkembangnya trend pada sebuah musik, terutama di dunia pop western. Hal tersebut menjadi tantangan untuk radio Gen 98.7 FM Jakarta dan program siaran DJ Sore untuk memutar otak bagaimana mempertahankan pendengar mereka tanpa mengubah konsistensi radio yang memiliki visi memutarkan $80 \%$ lagu pop Indonesia. Munculnya tantangan dan hambatan tersebut kemudian dibahas di evaluasi. Pada hal ini, evaluasi dilakukan program DJ Sore untuk mengetahui sejauh mana proses perencanaan yang telah dilakukan apakah sudah sesuai dengan rencana yang telah dibuat, dan untuk membahas kesalahan apa yang terjadi. Hal tersebut dilakukan guna pengelola program dapat segera mengatasi kesalahan yang terjadi agar tidak terjadi lagi di kemudian hari.

\section{SIMPULAN}

Dari penelitian yang telah dilakukan mengenai strategi komunikasi siaran radio Gen 98.7 FM Jakarta dalam program DJ Sore untuk mempertahankan pendengar, dapat disimpulkan bahwa strategi yang dilakukan program siaran DJ Sore meliputi perencanaan (planning), pengorganisasian (organizing), pelaksanaan (actuating), pengawasan (controlling) dan evalusasi (evaluating). Perencanaan yang dilakukan program siaran DJ Sore untuk mempertahankan pendengarnya ialah melaksanakan rapat yang dilakukan setiap hari dengan waktu yang fleksibel guna mendapatkan ide-ide mengenai peristiwa yang sedang dinikmati khalayak yang akan dibuat ke sebuah naskah siaran.

Kemudian melakukan penyesuain karakter pada penyiar agar materi yang disiarkan dapat diterima oleh pendengar dengan baik. Kemudian pengorganisasian (organizing) dimana program siaran DJ Sore memiliki crew-crew yang dilihat dari kredibilitas mereka sesuai dengan tugas dan tanggung jawab yang diberikan. Hal tersebut diperhatikan oleh Kepala program untuk meminimalisir kesalahan yang bisa saja terjadi di program siaran DJ Sore. Namun, pada dasarnya, sebuah program tidak luput dari hambatan dan tantangan yang harus dihadapi. Fenomena tersebut terjadi pada saat tahap pelaksanaan dilakukan. Dimana ditemukan hambatan dan tantangan seiring berjalannya program siaran DJ Sore. Maka dari itu, perlu diadakan pengawasan (controlling) yang dilakukan oleh produser pada program siaran DJ 
Sore, guna mengetahui sejauh mana hambatan tersebut mengganggu jalannya program siaran DJ Sore. Pengawasan yang dilakukan program siaran DJ Sore juga berguna untuk mengontrol kinerja para crew serta kesalahan apa saja yang terjadi di program siaran DJ Sore. Semua hal tersebut kemudian akan dibahas di tahap evaluasi. Yaitu membahas apa saja segmen-segmen yang berhasil disukai para pendengar, materi apa saja yang masih kurang, hingga bagaimana kinerja seluruh crew dalam membantu jalannya program siaran DJ Sore di radio Gen 98.7 FM ini untuk mempertahankan pendengar. Sehingga strategi komunikasi yang dilakukan program DJ Sore untuk mempertahankan pendengar berhasil dilakukan. Dimana hasil dari data pendengar DJ Sore yang di dapat penulis saat melakukan observasi di kantor radio Gen 98.7 FM Jakarta menunjukan pendengar DJ Sore mampu bertahan. Yakni berada diangka 1.225.000 pendengar pada tahun 2017, 1.430 .000 pendengar pada tahun 2018 dan 1.500.000 pendengar di tahun 2019.

Dapat diartikan berdasarkan hasil analisis wawancara bersama key informan I, Suluh Bagus, key informan II, Leo Utomo dan juga informan, Yuri Giantini, peran penyiar dan segmen-segmen yang ada di program siaran DJ Sore merupakan faktor utama bertahannya para pendengar. Hal tersebut dapat dilihat dari wawancara dengan pendengar,Yuri Giantini yang mengatakan bahwa ia mendengarkan program DJ Sore lima kali dalam seminggu untuk mendengarkan guyonan Leo dan Patra. Serta segmen Puisi Senja yang diarasa unik dan berbeda dari segmen yang ada di program siaran sore lainnya.

\section{DAFTAR PUSTAKA}

Arni. Muhammad. (2004). Komunikasi Organisasi. Jakarta: PT Bumi Aksara

Effendi, Uchjana, Onong. (2000). Dinamika Komunikasi. Bandung: PT Remaja Rosdakarya

Kartikawati, Dwi, Radjagukguk, Luciana, Djudjur, Sriwartini, Yayu. (2019). Strategi Komunikasti Multikultural di Sekolah Inklusi. Wedung: CV Lentera Kata

Miles, B. Mathew dan Michael Huberman. (1992). Analisis Data Kualitatif Buku Sumber Tentang Metode-metode Baru. Jakarta: UIP

Moleong, J, Lexy. (2006). Meode Penelitian Kualitatif. Bandung: PT Remaja Rosdakarya.

Pace, R. Wayne, Brent D. Peterson, and M. Dallas Burnett. (1979). Techniques for Effective Communication. Addison-Wesley Publishing Compan.

Suhandang, Kustadi. (2014). Strategi Dakwah: Penerapan Strategi Komunikasi Dalam Dakwah. Bandung. Rosdakarya. 
Terry, R. George. (2006). Dasar-dasar Manajemen. Jakarta: PT Bumi Aksara

Terry, R. George. (1953). Principle of Management. Irwin Series in Industrial Engineering and Management.

Onong, Effendy Uchjana. (1992). Ilmu Komunikasi Teori dan Praktik. Bandung: Rosdakarya. 